\section{Case Reports in Neurology}

Case Rep Neurol 2020;12:4-8

DOI: 10.1159/000506763

Published online: December 14, 2020
(C) 2020 The Author(s)

Published by S. Karger AG, Basel www.karger.com/crn

This article is licensed under the Creative Commons Attribution-NonCommercial 4.0 International License (CC BY-NC) (http://www.karger.com/Services/OpenAccessLicense). Usage and distribution for commercial purposes requires written permission.

\title{
Acute Ischemic Stroke in Term Pregnancy Treated with Recombinant Tissue Plasminogen Activator
}

\author{
Sanjith Aaron ${ }^{a} \quad$ Pavitra Ratna Mannam ${ }^{b} \quad$ Atif Shaikh $^{a}$ \\ Arun Mathai Mani ${ }^{a} \quad$ Deepti Bal ${ }^{\mathrm{a}}$ Jeyaraj Durai Pandian ${ }^{\mathrm{c}}$ \\ aDepartment of Neurology, Christian Medical College, Vellore, India; bepartment of \\ Radiology, Christian Medical College, Vellore, India; 'Department of Neurology, Christian \\ Medical College, Ludhiana, India
}

\section{Keywords}

Acute ischemic stroke $\cdot$ Pregnancy $\cdot$ Recombinant tissue plasminogen activator

\begin{abstract}
Recombinant tissue plasminogen activator (rtPA) may be considered in acute ischemic strokes (AIS) occurring in pregnancy. This recommendation is based on case reports which had demonstrated the efficiency and safety of rtPA in early pregnancy. However, most of the pregnancy-related strokes occur in the peripartum period. There is a paucity of literature on the management of AIS in this clinically relevant period of pregnancy; with only 2 case reports describing the use of IV rt-PA in the last trimester. Here, we report a case of AIS in a full-term pregnancy treated successfully with intravenous rt-PA. The patient went on to have an uncomplicated vaginal delivery after $72 \mathrm{~h}$ post thrombolysis. To the best of our knowledge, this is only the third such case in the English literature.
\end{abstract}




\section{Case Reports in Neurology}

Aaron et al:: Acute Ischemic Stroke in Term Pregnancy Treated with Recombinant Tissue Plasminogen Activator

\section{Introduction}

Stroke can affect up to 30.0 per 100,000 pregnancies. Ischemic strokes, cerebral venous sinus thrombosis and haemorrhagic strokes contributing equally [1].

When an acute ischemic stroke (AIS) occurs in pregnancy within the window for thrombolytic therapy, as per the 2018 AHA Guidelines [2], IV rt-PA administration may be considered when the anticipated benefits outweigh the anticipated increased risks of uterine bleeding. However, it should be noted that these recommendations have a low quality of evidence due to data limited mainly to case reports and case series (Level of Evidence C-LD) and class of evidence IIb which implies that the usefulness/efficacy is less well established by evidence/opinion.

Another major drawback for these recommendations is that the majority of the strokes in pregnancy usually occur in the last trimester [3], while these recommendations are based on the use of IV rt-PA in cases where the stroke had occurred in early pregnancy [1, 4-9]. To the best of our knowledge, there are only 2 case reports which describe the use of IV rt-PA in the last trimester $[10,11]$.

Here, we report a case of AIS in a full-term pregnancy treated successfully with intravenous rt-PA and the patient having an uncomplicated normal vaginal delivery after $72 \mathrm{~h}$.

\section{Case Report}

A 35-year-old female presented with sudden right-sided weakness and inability to speak within $1 \mathrm{~h}$ after the onset of her symptoms. She was pregnant (G5 P4 L4) at 39+ weeks of gestation. The previous pregnancies were uneventful and there was no history of any co-morbidities.

On admission, the blood pressure was $126 / 70 \mathrm{~mm} \mathrm{Hg}$, the pulse was regular at $90 / \mathrm{min}$. She was fully conscious. The comprehension was intact, but she had severe expressive aphasia with speech limited to incomprehensible sounds and occasional single words. She had rightsided upper motor neurone type of facial weakness with grade $4 / 5$ power on the right side. The NIHS score was 11.

MRI brain (see Fig. 1a) showed normal major intracranial arteries; however, there was marked paucity of the distal branches of the left MCA with diffusion restriction and swelling in the left insular cortex and adjacent frontal lobe (see Fig. 1b, c).

There was mild FLAIR hyperintensity with vessels appearing hyperintense (see Fig. 1d).

She was given IV thrombolysis with $0.9 \mathrm{mg} / \mathrm{kg}$ alteplase $(110 \mathrm{~min}$ from the onset of her symptoms). Her right hemiparesis improved fully and in the subsequent days, the language functions also improved and she was able to say 3-4 meaningful words and occasional phonemic paraphasia and by the second day of admission. Foetal well-being was assessed periodically in the ward following the thrombolysis.

A repeat MRI done after $24 \mathrm{~h}$ showed better visualization of the distal branches of the left MCA (Fig. 2a) and significant reduction in the degree of swelling and FLAIR hyperintensity (Fig. 2b-d). On the third day after her acute stroke, she went into spontaneous labour and had a normal vaginal delivery. The post-partum period was uneventful.

At the 3-month follow-up, she had only word finding difficulty for low frequency words and no weakness.

\section{Karger'=}




\section{Case Reports in Neurology}

Aaron et al:: Acute Ischemic Stroke in Term Pregnancy Treated with Recombinant Tissue Plasminogen Activator

The Cardiac ECHO and transcranial Doppler bubble study ruled out any cardiac source for emboli or right to left shunt. All workup for primary or secondary vasculitis, and hypercoagulable states were negative. The patient was continued on aspirin and is followed up.

\section{Discussion}

When confronted with an AIS in pregnancy, it is necessary to consider not only the usual aetiologies for an ischemic stroke, but also causes specific to pregnancy like peripartum cardiomyopathy, amniotic fluid embolism, etc., which may have caused the stroke. Also in pregnancy, some conditions like pre-eclampsia, eclampsia, choriocarcinoma, etc., can lead to stroke-like symptoms. Some of these aetiologies can be in itself a contraindication for thrombolytic therapy and some unlikely to respond to rt-PA. If there are no contraindications, rt-PA can be considered after weighing the risk and benefits [2].

Even though most strokes in pregnancy occur in the last trimester, there is a paucity of literature on the use of rt-PA in this part of pregnancy. There are only 2 case reports which describe benefits of rt-PA in the last trimester. Also as in any AIS patient, rt-PA has the risk of intracranial haemorrhage (ICH).

During this period of pregnancy, the main concerns of rt-PA therapy is uterine bleed [10] and its subsequent complications. Also the stress of stroke can induce labour and rt-PA therapy can increase bleeding during delivery and especially in cases where a caesarean section is warranted in the immediate post-thrombolytic therapy setting.

Mantoan et al. [11] reported a case of left middle cerebral artery stroke treated successfully at 36 weeks gestation. Another case was reported by Ritchie et al. [12] where rt-PA was given at 39 weeks and the patient subsequently made a full recovery and went on to have a normal delivery.

The commonest causes for stroke in pregnancy are cardioembolic [1]; however, in a large proportion of cases (28-46\%), similar to our case, the cause may remain elusive.

Pregnancy has been regarded as a contraindication to IV tPA treatment in clinical trials. However, it is now considered a treatment option when benefit outweighs the risk. To the best of our knowledge, this is only the third case which describes the use of IV rt-PA in the last trimester. More such case reports shall help to establish the safety and efficacy of IV rt-PA use in full-term pregnancy.

\section{Statement of Ethics}

Informed consent was obtained from the patient to publish this case report with the relevant images.

\section{Conflict of Interest Statement}

The authors have no conflicts of interest or disclosures to declare.

\section{Karger'"}




\section{Case Reports in Neurology}

\section{Funding Sources}

No funding was received.

\section{Author Contributions}

Sanjith Aaron conceptualized idea for manuscript, literature review, drafted the paper, and final version and collected the data. Pavitra Ratna Mannam collected the data and made the figures and legends. Atif Shaikh revised the manuscript for intellectual content. Arun Mathai Mani revised the manuscript for intellectual content. Deepti Bal collected the data and made the figures and legends. Jeyaraj Durai Pandian revised the manuscript for intellectual content, contributed to the draft and approved the final version.

\section{References}

1 Swartz RH, Cayley ML, Foley N, Ladhani NN, Leffert L, Bushnell C, et al. The incidence of pregnancy-related stroke: A systematic review and meta-analysis. Int J Stroke. 2017 Oct;12(7):687-97.

2 Powers WJ, Rabinstein AA, Ackerson T, Adeoye OM, Bambakidis NC, Becker K, et al.; American Heart Association Stroke Council. American Heart Association Stroke Council. 2018 guidelines for the early management of patients with acute ischemic stroke: a guideline for healthcare professionals from the American Heart Association/American Stroke Association. Stroke. 2018 Mar;49(3):e46-110.

3 Salonen Ros H, Lichtenstein P, Bellocco R, Petersson G, Cnattingius S. Increased risks of circulatory diseases in late pregnancy and puerperium. Epidemiology. 2001 Jul;12(4):456-60.

4 Landais A, Chaumont H, Dellis R. Thrombolytic Therapy of Acute Ischemic Stroke during Early Pregnancy. Stroke Cerebrovasc Dis. 2018 Feb;27(2):e20-3.

5 Li Y, Margraf J, Kluck B, Jenny D, Castaldo J. Thrombolytic therapy for ischemic stroke secondary to paradoxical embolism in pregnancy: a case report and literature review. Neurologist. 2012 Jan;18(1):44-8.

6 Yamaguchi Y, Kondo T, Ihara M, Kawamata J, Fukuyama H, Takahashi R. [Intravenous recombinant tissue plasminogen activator in an 18-week pregnant woman with embolic stroke]. Rinsho Shinkeigaku. 2010 May;50(5):315-9. Japanese.

7 Hori H, Yamamoto F, Ito Y, Hashimoto Y, Hirano T, Uchino M. [Intravenous recombinant tissue plasminogen activator therapy in a 14-week pregnant woman with embolic stroke due to protein S deficiency]. Rinsho Shinkeigaku. 2013;53(3):212-6. Japanese.

8 Tassi R, Acampa M, Marotta G, Cioni S, Guideri F, Rossi S, et al. Systemic thrombolysis for stroke in pregnancy. Am J Emerg Med. 2013 Feb;31(2):448.e1-3.

9 Hirano T. Acute revascularization therapy in pregnant patients. Neurol Med Chir (Tokyo). 2013;53(8):531-6.

10 Murugappan A, Coplin WM, Al-Sadat AN, McAllen KJ, Schwamm LH, Wechsler LR, et al. Thrombolytic therapy of acute ischemic stroke during pregnancy. Neurology. 2006 Mar;66(5):768-70.

11 Mantoan Ritter L, Schüler A, Gangopadhyay R, Mordecai L, Arowele O, Losseff N, et al. Successful thrombolysis of stroke with intravenous alteplase in the third trimester of pregnancy. J Neurol. 2014 Mar;261(3):632-4.

12 Ritchie J, Lokman M, Panikkar J. Thrombolysis for stroke in pregnancy at 39 weeks gestation with a subsequent normal delivery. BMJ Case Rep. 2015 Aug;2015:bcr2015209563. 
Case Reports in Neurology

\begin{tabular}{l|l}
\hline Case Rep Neurol 2020;12:4-8 \\
\hline DOI: 10.1159/000506763 & $\begin{array}{l}\text { @ 2020 The Author(s). Published by S. Karger AG, Basel } \\
\text { www.karger.com/crn }\end{array}$ \\
\hline
\end{tabular}

Aaron et al:: Acute Ischemic Stroke in Term Pregnancy Treated with Recombinant Tissue Plasminogen Activator
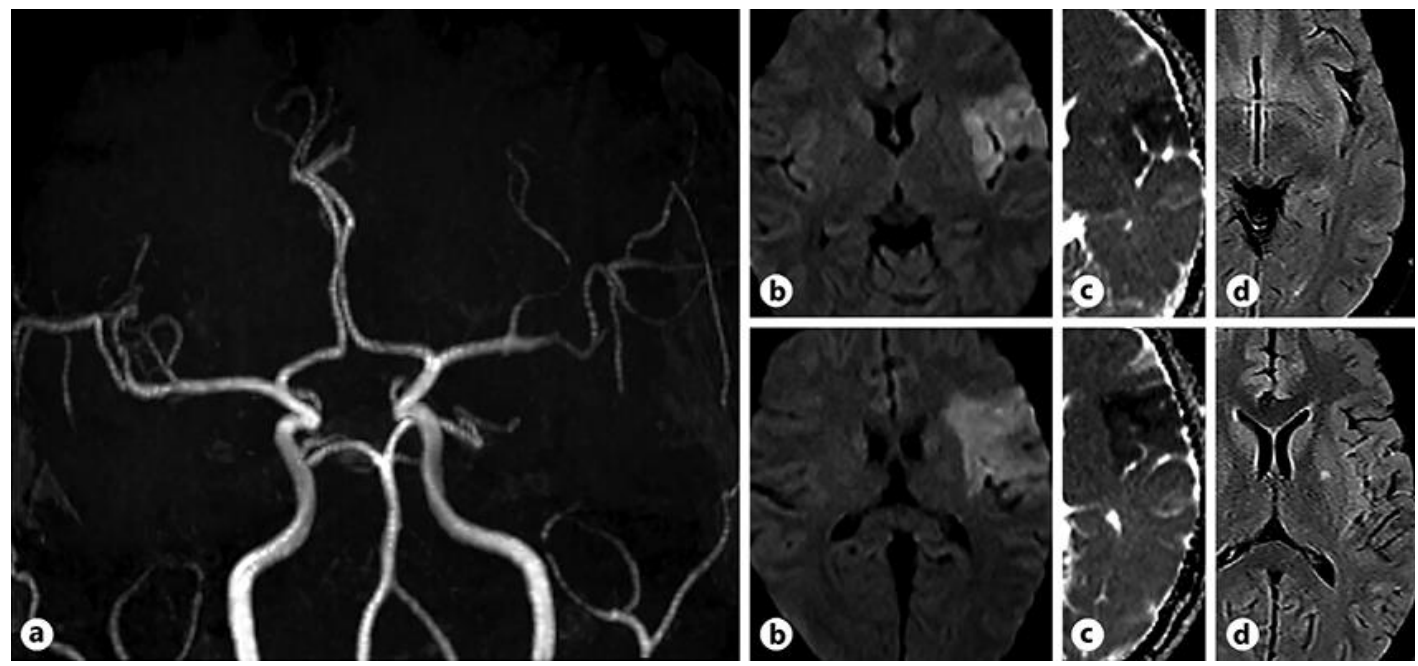

Fig. 1. a MRA showing paucity of the distal branches of the left MCA, b DWI, and c ADC sequences showing diffusion restriction and swelling in the left insular cortex and adjacent frontal lobe. $\mathbf{d}$ FLAIR images showing hyperintense signals with vessels appearing hyperintense.
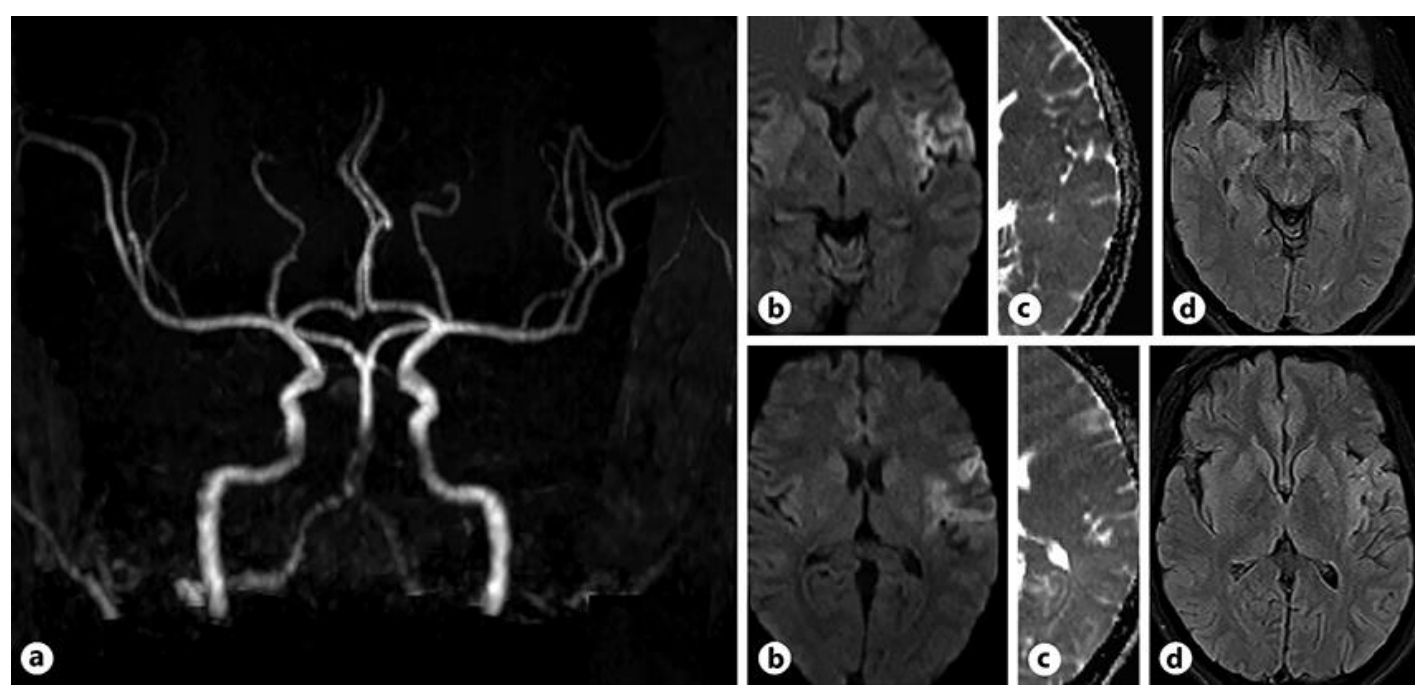

Fig. 2. a MRA showing better visualization of the distal MCA branches, $\mathbf{b}$ DWI, and $\mathbf{c}$ ADC sequences showing significant reduction in the diffusion restriction, and $\mathbf{d}$ FLAIR sequence showing decrease in the hyperintense signals. 